\title{
MESTRADOS PROFISSIONAIS: A ITINERÂNCIA DA ÁREA DE EDUCAÇÃO E OS LEGADOS DA UNIVERSIDADE DO ESTADO DA BAHIA
}

Tânia Maria Hetkowski (UNEB)*

Tânia Regina Dantas (UNEB)**

\section{RESUMO}

Este artigo apresenta a itinerância e os legados dos Programas de Pós-Graduação em Educação, na modalidade profissional, que são ofertados no Departamento de Educação, Campus I, da Universidade do Estado da Bahia. Objetiva, primeiramente, rememorar a criação dos Mestrados Profissionais no Brasil, a fim de destacar a sua trajetória, legitimação e consolidação em todo o território brasileiro e, posteriormente, demonstrar as principais características dos dois programas: Gestão e Tecnologias Aplicadas à Educação (GESTEC) e Educação de Jovens e Adultos (MPEJA). Do ponto de vista metodológico, este é um trabalho descritivo, com destaque para alguns dados quantitativos e qualitativos, coletados para embasá-lo, que se subsidia na legislação que ampara a criação e a implantação desses programas, que visa promover uma reflexão sobre as políticas públicas no campo da pós-graduação em educação, chamando atenção para a relevância de ofertar esses cursos, especificamente nesta modalidade, sobretudo para os professores e gestores da educação básica, principais protagonistas e demandantes destes cursos. Autores como Cevallos e Passos (2012), Ribeiro (2006), André (2001), Nóvoa (2009), Machado (2009), Haddad e Di Pierro (1999) e Flecha (1999) dialogam com as pesquisadoras na análise dos dados. Os resultados mais evidentes são decorrentes de práticas educativas inovadoras, dos trabalhos de curso realizados pelos estudantes, incremento da pesquisa educacional, dados novos e informações atualizadas sobre educação, tecnologia, gestão e Educação de Jovens e Adultos (EJA), bem como novas metodologias e artefatos tecnológicos que são impulsionados pelas investigações realizadas por discentes com a orientação dos docentes credenciados nos referidos programas.

Palavras-chave: Mestrados profissionais. Educação. Gestão.

\section{ABSTRACT}

\section{PROFESSIONAL MASTERS: THE ITINERARY OF THE EDUCATION AREA AND THE LEGACIES OF THE STATE UNIVERSITY OF BAHIA}

This article show the itinerancy and the legacy of the post-graduate program in Education, in professional modality, offered by the Education Department, Campus I, at State University of Bahia. Its aims, first, to remember the origin of Professional

* Professora dos Programas de Pós-Graduação Educação e Contemporaneidade (PPGEduC) e Gestão e Tecnologias Aplicadas à Educação (GESTEC) da Universidade do Estado da Bahia (UNEB). Coordenadora Adjunta da Área de Educação na CAPES. E-mail: hetk@uol.com.br

** Coordenadora e Professora do Mestrado Profissional em EJA da Universidade do Estado da Bahia (UNEB). E-mail: taniaregin@hotmail.com 
Master in Brazil, highlighting its path, legitimization and consolidation around the brazilian territory and then later, emphasize the main features of the two programs : Management and Technologies Applied to Education (GESTEC) and Youth and Adults Education (MPEJA). From a methodological point of view, this is a descriptive paper based on the law that supports the creation and implementation of these programs, which aims to promote a reflection on public policies in the area of postgraduate education, drawing attention to the importance in offering these courses, specifically in this mode, especially for teachers and managers of basic education, key players and applicants of these courses. The most evident results are due to innovative educational practices, increase of educational research, new data and updated information about education, technology, management and youth and adult education (EJA), as well as new methodologies and technological artifacts that are driven by investigations carried out by students with the guidance of teachers accredited in those programs Keywords: Professionals Masters. Education. Manegment.

\section{RESUMEN}

\section{MAESTRIAS PROFESIONALES: LA ITINERANCIA DEL AREA DE EDUCACIÓN Y EL LEGADO DE LA UNIVERSIDAD DEL ESTADO DE BAHÍA}

Este artículo presenta la itinerancia y los legados de los Programas de Postgrado en Educación en la modalidad Profesional, que se ofrecen en el Departamento de Educación, Campus I, de la Universidad del Estado de Bahía. Su objetivo es en primer lugar, recordar la creación de las Maestrias Profesionales en Brasil, con el fin de poner de relieve su trayectoria, legitimación y consolidación en todo el territorio brasilero y posteriormente demostrar principales características de los dos programas: Gestión y Tecnologías Aplicadas a la Educación (Gestec) y Educación Jóvenes y Adultos (MPEJA). Desde un punto de vista metodológico, se trata de un estudio descriptivo, destacando algunos datos cuantitativos y cualitativos recogidos para apoyar este artículo, que subvenciona la legislación que apoya la creación y ejecución de estos programas, cuyo objetivo es promover una reflexión sobre la política curso de postgrado en la educación, llamando la atención sobre la importancia de ofrecer estos cursos, específicamente en esta modalidad, especialmente para los profesores y los administradores de la educación básica, principales actores y demandantes de estos cursos. Autores como Cevallos y Pasos (2012), Janini (2006), André (2001), Novoa (2009), Machado (2009), Haddad y Di Pierro (1999), Ramón Flecha (1999) dialogan en el análisis de los dátos con las investigadoras. Los resultados más evidentes se deben a las prácticas educativas innovadoras de los trabajos de curso realizados por los estudiantes, el aumento de la investigación educativa, los nuevos datos e información actualizada sobre educación, tecnología, gestión y EJA, así como nuevas metodologías y artefactos tecnológicos que son impulsados por las investigaciones realizadas por los estudiantes con la guía de maestros certificados en estos programas.

Palabras claves: Profesionales Maestros. Educación. Gestión.

\section{Introdução}

Os Mestrados Profissionais em Educação (MPE) vêm se afirmando nas principais discussões sobre a Área, colocando em pauta problemas, en- traves, reivindicações, ações, projetos e propostas desta modalidade de cursos stricto sensu nos principais fóruns, encontros e seminários (locais, 
regionais e nacionais) que tratam da formação dos profissionais da Educação e de políticas públicas a esta relacionadas. Nesses espaços, o coletivo de representantes dos MPE foi fortalecido e demonstrou grande potencial articulador a partir da criação, em 2012, de um fórum específico para pautar as discussões e estratégias de reconhecimento, crescimento, integração nacional e mediações com órgãos reguladores e de fomento, denominado Fórum Nacional dos Mestrados Profissionais em Educação (FOMPE), idealizado durante a reunião do Fórum Nacional dos Coordenadores de Programas de Pós-Graduação em Educação da ANPEd (FORPRED), em Goiânia-GO.

O FOMPE tem se consolidado como um espaço plural, aberto ao diálogo, à participação de gestores, professores, alunos e pesquisadores que desejam conhecer e participar das dinâmicas dos cursos e do Fórum. Objetivando "caracterizar percursos, condições, necessidades, desafios, perspectivas e proposições dos MPE no Brasil, a partir do levantamento e da coleta de dados, da análise de documentos e marcos históricos [...]" (FÓRUM NACIONAL DE COORDENADORES DE PROGRAMAS DE PÓS-GRADUAÇÃO EM EDUCAÇÃO DA ANPEd, 2013, p. 1).

Após o FORPRED 2012, foi elaborado o documento intitulado "Relatório das Condições e Perspectivas dos Mestrados Profissionais na Área de Educação", com o propósito de subsidiar as discussões para consolidação e fortalecimento dos MPE junto à CAPES e no âmbito da ANPED/ FORPRED, no que concerne às demandas e necessidades emergentes nesses programas.

$O$ relatório trata de um breve histórico de implantação dos Mestrados Profissionais em Educação no Brasil, demonstra a evolução dos cursos e destaca "pontos divergentes e convergentes na ANPED e no FORPRED acerca da implantação, implementação, funcionamento, reconhecimento desta modalidade stricto sensu" (FORPRED, 2013 , p. 4). Outro documento de destaque nesse período foi o parecer elaborado pela Comissão do FORPRED em 2011, encaminhado à Área de Educação da CAPES, que apresenta um histórico do surgimento e regulamentação dos Mestrados Profissionais (MP), resgata a orientação da Portaria $n^{\circ} 07 / 2009$ para a criação de propostas dos
Mestrados Profissionais, destacando objetivos e as modalidades dos trabalhos de conclusão de curso, porém analisa de forma restritiva e sem ampliação a relação dos "MPs como política pública para qualificação de docentes do ensino básico nas redes públicas". (FORPRED, 2011, p. 6).

Assim, este artigo tem como pretensão rememorar o nascedouro dos Mestrados Profissionais no Brasil, visando sua trajetória, legitimação e consolidação no território brasileiro. Ademais, também busca apresentar a trajetória dos Programas de Pós-Graduação nesta modalidade na Universidade do Estado da Bahia (UNEB): Gestão e Tecnologias Aplicadas à Educação (GESTEC) e Educação de Jovens e Adultos (MPEJA).

\section{Mestrados Profissionais: a itinerância da Área de Educação}

A história com a Pós-Graduação stricto sensu inicia em 1965, com o Parecer do Conselho Federal de Educação (CFE) n ${ }^{\circ}$ 977, Parecer Sucupira, o qual já apontava para a necessidade de criação de cursos orientados à formação profissional para o mercado de trabalho e a formação de pesquisadores para a vida acadêmica (BRASIL, 1965). Porém somente nos anos 1990, através da Coordenação de Aperfeiçoamento de Pessoal de Nível Superior (Capes) retornam as discussões e necessidades de criação de cursos de mestrados em uma modalidade diferenciada, denominada Mestrados Profissionais.

Dessa necessidade surge a Portaria Capes n ${ }^{\circ} 47$, de 1995, que aprova a flexibilização da modalidade de programas stricto sensu e o perfil dos alunos ingressantes e egressos desses cursos; a Portaria Capes $n^{\circ} 80$, de 1998, vem reconhecer os Mestrados Profissionais; e as Portarias Normativas $n^{\circ}$ 07 e $n^{\circ} 17$, de 2009, regulamentam os Mestrados Profissionais no âmbito da Capes. Para Ribeiro (2006, p. 313-314),

[...] com base no poder regulamentar ínsito à agência, que o MP apareceu na legislação brasileira. Daí, também, que o MP não possa ser discriminado de maneira negativa, por exemplo em concursos públicos ou de seleção para o doutorado. Tal assunto foi decidido pelo Conselho Nacional de Educação e ficou bastante claro que, numa seleção, o edital não pode exigir tal ou qual tipo de mestrado. 
Dessa forma, foram a legitimação dos MP e a criação do Fórum Nacional dos Mestrados Profissionais (FOPROF), em 2006, que selaram uma história de consolidação dos mestrados profissionais em todo o território nacional. Nesse cenário, as instituições pioneiras foram a Universidade Federal da Bahia (UFBA), a Universidade Federal do Rio Grande do Sul (UFRGS), a Fundação Getúlio Vargas (FGV/EBAPE) e a Escola de Administração de Empresas de São Paulo (EAESP). Hoje os MP somam mais de 600 programas, reconhecidos pela Capes e presentes nas cinco regiões do Brasil.

Motivados por outras áreas do conhecimento, os professores e pesquisadores da Educação tiveram os primeiros programas criados no ano de 2009, na Universidade Federal de Juiz de Fora, e na Universidade do Estado da Bahia no ano de 2010. Essas iniciativas mobilizaram a área de Educação, e no ano de 2011, no FORPRED foi nomeada uma Comissão que gerou o primeiro documento com o objetivo de refletir como a Área na Capes poderia construir e assumir uma concepção de Mestrado Profissional a ser oferecido à qualificação dos professores da Educação Básica, e aponta os objetivos do curso, organização curricular, Trabalho de Conclusão de Curso, perfil do egresso, lugar da pesquisa, recursos orçamentários, duração formativa, entre outros posicionamentos ainda imaturos sobre o entendimento e função desta modalidade.

O segundo documento, baseado neste primeiro, apresentando no ano de 2012 na Universidade de Brasília (UnB), destacava a política dos Mestrados Profissionais em Educação, entendida como: política de governo; destinada aos profissionais de educação básica; com indicadores diferenciados de avaliação; composta por um corpo docente de doutores; com ênfase na pesquisa das práticas educativas; mantida sua autonomia como programa; exigida formação pedagógica do corpo docente; com destaque nos cursos presenciais; garantida as condições de trabalho para o profissional da educação básica; apoiada pelas ações da ANPEd e outras instâncias que garantiriam a realização do curso; planejamento de carreira docente para a permanência do egresso na educação básica; garantia de bolsas de estudo para os professores advindos da rede básica de ensino.
O terceiro documento, denominado Relatório das Condições e Perspectivas dos Mestrados Profissionais na Área de Educação, da Capes, ${ }^{1}$ de 2013, tinha como objetivo caracterizar os percursos, necessidades, desafios, perspectivas e proposições dos Mestrados Profissionais em Educação (MPE) no Brasil, a partir do levantamento das condições e realidade dos programas stricto sensu, nesta modalidade, aprovados e em funcionamentos nas cinco regiões do Brasil. Neste documento a Comissão salienta que o grande equívoco dos sujeitos é discutir o Mestrado Profissional tomando como referência as experiências da modalidade acadêmica, o que impede de percebê-lo como potencial e como estratégica à formação profissional com naturezas e singularidades próprias. Para Menandro (2010, p. 370),

[...] no Mestrado Profissional, assim como no Acadêmico deve existir formação metodológica e pesquisa. [Esta modalidade] é caracterizada por maior dinamismo, pois a adaptação é uma de suas marcas, já que é movido por demandas que lhe são endereçadas.

Esse documento, entendido como marco na Área de Educação, aborda o desvelamento dos Mestrados Profissionais em Educação no Brasil, argumenta e localiza a identidade acadêmica desta modalidade na Área da Educação, apresenta o Estatuto dos Mestrados Profissionais na Área da Educação e aponta o cenário destes no território brasileiro, através da seguinte análise:

Distribuição dos cursos por ano de início: expansão e crescimento em média de $75,6 \%$ ao ano;

Distribuição dos cursos por estados e categoria administrativa: concentração de 50\% em instituições federais; média de 30\% em instituições estaduais e; $20 \%$ em instituições comunitárias e particulares;

Análise de algumas variáveis: o público alvo é predominante composto por professores e profissionais da educação básica; os focos temáticos prevalecem na formação de professores e na gestão da educação; os formatos de Trabalho de Conclusão de Curso se consolidam através de formatos de projetos, relatórios técnicos, modelagens, com ênfase nas dissertações; Impactos esperados: predomina a qualificação de

1 Disponível em: http://www.uneb.br/gestec/files/2014/05/MProfissional-FORPRED-GOIANIA.pdf. 
professores e de profissionais da educação para a rede de ensino, especialmente à Rede Pública;

Dificuldades apontadas pelos responsáveis pelos cursos: $68 \%$ assinalam a falta de financiamento para o curso e a inexistência de bolsas para alunos. (Capes, 2013).

O documento ainda destaca sobre as características peculiares do Mestrado dirigido à formação profissional, em nível stricto sensu e enfatiza que os cursos nesta modalidade, recomendados, avaliados pela Capes e credenciados pelo Conselho Nacional de Educação (CNE) a partir da Portaria Normativa $\mathrm{n}^{\circ} 07 / 2009$, passam a ter validade nacional, concedendo ao seu detentor os mesmos direitos que possuem os portadores da titulação nos cursos acadêmicos. $\mathrm{O}$ título, portanto, vai permitir ao portador o ingresso nos cursos de doutorado e no trabalho de docência no Ensino Superior, não podendo ser privado desse direito por qualquer razão (FÓRUM NACIONAL DOS PROGRAMAS DE PÓS-GRADUAÇÃO EM EDUCAÇÃO, 2011). "Isso não é nada trivial, e por isso mesmo a Capes tem enfatizado que o mestrado profissional não pode ser visto como uma titulação menor. Alguns de seus desafios são tão altos ou mesmo maiores que o do mestrado acadêmico" (RIBEIRO, 2006, p. 315).

Hoje a trajetória dos Mestrados Profissionais em Educação parece contínua e serena, mas nesse itinerário se manifestaram muitos pesquisadores, como Virmond (2002) e Boufleur (2003), contrários à implementação desta nova modalidade na área de Educação, pois ainda se detinham em ideais e concepções do século XVIII e instalaram receios, críticas e desconfianças no meio acadêmico e aos sujeitos desejantes em cursar a modalidade profissional nesta área. Para Romão e Mafra (2016, p. 12), "os experts em determinado aparelho de Estado sempre temem as mudanças, com medo de perderem os postos ou os privilégios acumulados ao longo dos anos, na medida em que percebem que as inovações podem esvaziar suas tradicionais funções".

Superada as críticas e as exposições negativas, os 43 (quarenta e três) programas na Área de Educação, nesta modalidade, têm conquistado distinções no seu processo identitário; na sua função formado- ra aos profissionais que atuam na educação; no seu sentido integrador entre Universidade e Escolas das Redes de Ensino; na produção intelectual e na geração de produtos (frutos de ações teórico-práticas de alunos e professores); e na inter-relação entre pesquisa, ensino e inovações educacionais. Essa "criação genuinamente brasileira", como definem Romão e Mafra (2016), tem reconhecimento e legitimidade na/da comunidade educacional, como é o caso dos Programas de Pós-Graduação da Universidade do Estado da Bahia: GESTEC e MPEJA.

\section{Mestrados Profissionais em educação na UNEB: GESTEC E MPEJA}

\section{O GESTEC}

O Programa de Pós-Graduação Gestão e Tecnologias Aplicadas à Educação (GESTEC) da Universidade do Estado da Bahia (UNEB), vinculado ao Departamento de Educação (DEDC), Campus I - Salvador-BA foi o segundo programa stricto sensu do Brasil, constituído como mestrado profissional na área de Educação na Capes, e tem como finalidade a produção de conhecimentos, a atualização permanente dos avanços da ciência e das tecnologias, a capacitação e o aperfeiçoamento de profissionais na área da gestão educacional e processos tecnológicos, bem como o desenvolvimento da pesquisa aplicada e a inovação tecnológica no campo da educação.

Esse curso é um espaço acadêmico-científico propositivo à construção e ao aprofundamento das relações entre universidade e educação básica, com inumeráveis possibilidades de temáticas derivadas do extenso campo de atuação dos professores e profissionais da educação, em consonância com o Plano Nacional de Pós-Graduação 2011-2020 (BRASIL, 2010), que considera a educação básica um novo desafio para o sistema nacional de pós-graduação no Brasil. Para Cevallos e Passos (2012, p. 807), “o Mestrado Profissional pode criar oportunidades de reflexão sobre suas práticas e compartilhamento dos desafios vividos, perspectivando a construção e consolidação de uma postura criativa e integradora para a atividade educativa".

Esse desafio também proporciona espaços para estudos sobre a gestão da educação superior, com ênfase nas universidades e instituições não universitárias mantidas pelo setor público, a partir da 
complexidade destas instituições: na formação de profissionais; no incentivo à pesquisa com participação da comunidade; na dificuldade de interação com os fazeres da educação básica; na qualificação de técnicos e dirigentes universitários; e outras temáticas concernentes à realidade educacional.

Nesse ínterim, compreendemos que os processos formativos que envolvem as universidades e outros níveis de ensino incidem, diretamente, nos meandros da Educação Básica, aqui entendida como sustentação a outros níveis de ensino e, nesse sentido, evidencia-se o compromisso dos Mestrados Profissionais com a Educação Infantil, Ensino Fundamental, Ensino Médio e Ensino Profissional, os quais possibilitam o "ser graduando e pós-graduando" nas instâncias do ensino superior.

E pesquisar os meandros desses processos educativos demanda rigor investigativo na interpretação de suas histórias, linguagens, experiências, percursos e vivências com o mundo e com os sujeitos desse mundo. A hermenêutica da prática é a possibilidade de compreender e interpretar os espaços educacionais da gestão e da tecnologia, onde sujeitos modificam seu cotidiano através de práticas e de ações, as quais geram outros elementos que permeiam a vida individual ou coletiva, ou seja, esta modalidade stricto sensu demanda vivenciar a pesquisa implicada.

Há necessidade de repensar as exigências para uma dissertação de mestrado, pois em muitos programas de pós-graduação mantêm-se os mesmos padrões de 30 anos atrás, quando o mestrado era completado de 5 a 10 anos. Contudo, também não podemos abrir mão da qualidade, aceitando qualquer produto pela redução de prazo, sob a pena de desmoralizarmos totalmente a pesquisa (ANDRÉ, 2001).

Nesse sentido, a Portaria Normativa da Capes $\mathrm{n}^{\mathrm{o}}$ 17, de 2009, possibilita a construção de Trabalhos de Conclusão de Curso a partir: de processos e propositivas advindas da realidade educacional; das vivências e inovações de práticas pedagógicas; da exploração de tecnologias e dispositivos na comunidade escolar; das iniciativas que envolvam professores, alunos e comunidade; do desenvolvimento de tecnologias, modelagens e protótipos que atendam as demandas educacionais; da construção de projetos, propostas e perspectivas de inovação às ações e atividades de sala de aula e de gestão escolar; dos processos formativos à exploração de estratégias e procedimentos de ensino; e do envolvimento e mobilização de profissionais de diferentes áreas para "contaminar" a escola, os sistemas de ensino e as políticas públicas educacionais.

As pesquisas realizadas por Monteiro (2015), Araújo (2015), Moreira (2015), Mendes (2015), Freitas (2015), Correia (2015), Menezes (2016) e Marques (2015), dentre mais de uma centena de egressos, demonstram projetos relacionados às suas práticas como propostas à inovação educacional $\mathrm{e}$ ao desenvolvimento profissional como professores, as quais são pressupostos norteadores da identidade profissional do Curso, ampliam a capacidade crítica dos sujeitos na sua atuação profissional, e a materialização dessa transformação pode ser apresentada ao final do curso, conforme previsto na Portaria $\mathrm{n}^{\circ}$ 17 e no Regimento Interno do Curso.

Identificamos que nos TCC defendidos até o presente momento há interação e mediação dos processos e propositivas educacionais, entendidas no GESTEC como legados às redes de ensino do município e do estado da Bahia, representados por quatro grandes eixos: Educação e Processos Tecnológicos; Gestão e Avaliação da Educação; Inovação da Educação Básica; Educação, Meio Ambiente e Desenvolvimento Local. Pois "considerar o professor como investigador é uma posição política. É reconhecê-lo como um profissional que produz conhecimento" (CEVALLOS e PASSOS, 2012, p. 811).

Com essa intenção, o GESTEC consolidou-se na dinâmica do Departamento de Educação (DEDC - Campus I), lócus que oferece à comunidade cursos de graduação em Pedagogia, Psicologia, Filosofia e Ciências Sociais, potencializando a convivência entre pesquisadores doutores, doutorandos, mestres, mestrandos, especializandos e graduandos à formação de jovens pesquisadores e à cooperação acadêmica com outros departamentos, a exemplo do DCH e do DCET ${ }^{2}$. Para Fernandes (2015, p. 109),

[...] as universidades estariam não só estendendo a sua atuação ao campo profissional, mas também e, sobretudo, concedendo maior visibilidade às suas

2 Departamento de Ciências Humanas e Departamento das Ciências Exatas e da Terra. 
formas de inserção social, no sentido mais amplo do termo. Estariam, também, passando a desenvolver um modelo de formação profissional que pressupõe formas de engajamento em parcerias bilateral ou multilateralmente constituídas, rompendo, portanto, com o papel hegemônico e unilateral que historicamente lhe foi outorgado exercer.

Dessa forma, as Áreas de Concentração do GESTEC: Gestão da Educação e Redes Sociais e Processos Tecnológicos e Redes Sociais, agregam grupos de pesquisa, parcerias e ações que redimensionam a pesquisa, o ensino e a extensão. Nesse sentido, os grupos de pesquisa envolvem alunos de graduação, pós-graduação, educação básica e servidores da UNEB, e se constituem em vias efetivas de articulação entre universidade e comunidade. "Não haverá nenhuma mudança significativa se 'a comunidade dos formadores de professores' $\mathrm{e}$ a 'comunidade dos professores' não se tornarem mais permeáveis e imbricadas" (NÓVOA, 2009, p. 17). Neste ínterim, a participação em projetos de pesquisa tem proporcionado aos alunos de graduação seu envolvimento em eventos, minicursos, comunicações e publicações, constituindo uma base ampla de conhecimento à atuação profissional ou próspera para a carreira acadêmica.

Ademais, considerando que os objetivos do GESTEC buscam capacitar profissionais para intervir na realidade educacional nas diversas regiões do estado da Bahia, em especial em regiões marcadas pela pobreza, desigualdade social e pelos desequilíbrios regionais, visando à preservação do patrimônio cultural e do desenvolvimento humano à cultura, ciência e tecnologia, fortalecendo processos de construção científico-acadêmica. Nesse sentido, o GESTEC assumiu como compromisso, em cada processo seletivo, destinar um percentual de vagas aos professores e servidores técnico-administrativos da UNEB, por compreender que estes são profissionais da educação e que contribuem, de maneira efetiva, com a universidade na elevação da competência profissional à gestão e avaliação dos processos universitários e no desenvolvimento da ciência, tecnologia e inovação referente aos sistemas de informações acadêmicos e administrativos.

Podemos constatar esse compromisso através de pesquisas desenvolvidas por técnicos-administrativos no âmbito do GESTEC, tais como: Oliveira
(2013) desenvolveu uma ferramenta EAD para mediação tecnológica denominada GESMOODLE, destinada os cursos de graduação online; Gomes (2016) e Ramirez (2016) criaram e implementaram a Plataforma Pandora para a gestão do sistema de informações da Pós-Graduação stricto sensu da UNEB; Viana (2016) apresentou uma proposta à (re)composição documental para softwares educacionais ou sistemas informáticos; Silva (2015) gerou uma proposta que discute a política e a valorização dos servidores técnico-administrativos da UNEB; Miranda (2013) expôs um estudo de caso sobre o orçamento do Sistema Estadual de Educação Superior na Bahia, entre muitos outros trabalhos que demonstram o desenvolvimento profissional desses pesquisadores e o legado que proporcionam à UNEB.

O GESTEC, na sua função integradora e solidária, mantém uma aproximação com os programas na modalidade profissional, participa de ações para fortalecer a identidade e o estatuto dos MPE no Brasil, busca aproximação com mestrados e doutorados acadêmicos e considera como um dos seus principais compromissos a permuta e a integração com o sistema da pós-graduação no Brasil, em especial nas regiões Norte e Nordeste. Nesse sentido, é parceiro das dinâmicas da ANPEd, FORPRED Nacional e FORPRED Nordeste, e mobilizador do FOMPE.

A experiência, acumulada dos profissionais que atuam no GESTEC confirma a necessidade de tornar os sistemas de ensino e os ambientes de trabalho, principalmente no âmbito da educação básica, laboratórios vivos, instigando a ação universitária à imersão nas problemáticas da gestão e da aplicação de tecnologias digitais à educação. No contexto das tecnologias e da gestão, o GESTEC visa contribuir com o desenvolvimento de novos caminhos para o processo de construção do conhecimento, destacando as tecnologias digitais como propositivas que rompem a linearidade e instauram uma lógica hipertextual e interativa que possibilita a negociação contínua e o intercâmbio dos saberes, criando novas dinâmicas pedagógicas e profissionais, as quais são exponencialmente exploradas nas pesquisas implicadas com/na rede pública de ensino, agregando dispositivos tecnológicos, metodologias de projetos, métodos de 
gestão, desenvolvimento de jogos e simuladores, espaços de formação para professores, propositivas de avaliação educacional e outras propostas que envolvem alunos e sala de aula. Os MPE, como o GESTEC, não são melhores ou menos importantes que os demais programas, apenas são singulares e buscam exercer seu compromisso.

\section{O MPEJA}

Nesta seção, trataremos do Programa de Pós-Graduação em Educação de Jovens e Adultos - nível Mestrado Profissional (único programa no Brasil nesta área específica como profissional) recomendado, em 2012, pela Coordenação de Aperfeiçoamento de Pessoal de Nível Superior (Capes), tendo iniciado as suas atividades em 2013, no Departamento de Educação - Campus I da UNEB.

Intencionamos nesta seção do artigo aportar algumas considerações a respeito da criação dos Mestrados Profissionais (MPE) e contextualizar o surgimento da proposta de pós-graduação em Educação de Jovens e Adultos no âmbito das políticas de formação da Capes.

Ao longo da história da educação brasileira, a educação de jovens e adultos passou por várias fases, podendo-se verificar "a grande dificuldade de os programas destinados à educação de adultos cumprirem seus objetivos" (PEREIRA, 2007, p. 13), pois os projetos de governo até então implementados fundaram-se sobre uma concepção de educação que representa a educação popular, se assim devemos nomear este tipo de educação, como uma educação para os pobres, iletrados, como se o próprio letramento não se realizasse sem a aprendizagem dos códigos linguísticos, reduzindo, assim, a cultura e o próprio pensar como atributo ontológico do ser humano à cultura erudita, aprendida nos bancos escolares e acadêmicos.

A este respeito, Flecha e Mello (2012, p. 42) destacam que "no caso do Brasil, a EPEJA acompanha seu percurso de constantes lutas de superação de processos bastante intensos de opressão [...] descompromissados com a população e a garantia de seus direitos".

Os alunos de que trata a EJA são jovens e adultos trabalhadores, muitos com ampla experiência de vida e profissional, com expectativas de (re) inserção no mundo do trabalho, como acentua
Soares (2002), que aportam saberes populares oriundos dos seus "fazeres" e que procuram a escola na esperança de serem validados estes saberes e aproveitadas as suas experiências, na direção da melhoria da qualidade de vida.

Neste sentido, a formação de profissionais deve levar em consideração "a diversidade da clientela constituída por jovens e adultos trabalhadores, as suas peculiaridades, diferenças culturais, experiências de vida, histórias, saberes e características específicas [...]" (DANTAS, 2012, p. 151).

Entre os problemas apontados por Schmelkes (1996 apud PEREIRA, 2007) na Educação de Jovens e Adultos, estão: os parcos recursos destinados a essa educação, a falta de formação profissional nessa área específica e a descontinuidade das políticas públicas. Entretanto, conhecendo um pouco do interior da efetivação das políticas públicas para a classe trabalhadora, verifica-se, ainda, o mal uso ou malversação dos recursos aplicados nos projetos para a EJA como uma das causas extras do fracasso da maioria dos programas governamentais, os quais primam pelo controle formal ao invés do controle material, da efetiva consecução dos objetivos propalados na mídia, qual seja, de melhoria significativa da educação pública brasileira.

Contudo, como nos lembra Machado (2009), outros fatores não menos relevantes constituem o leque de dificuldades da Educação de Jovens e Adultos.

Há uma quase unanimidade na constatação das dificuldades enfrentadas pelos professores em sua prática e da necessidade de uma preparação específica dos professores que atuam em EJA, balizada por exemplos de experiências pesquisadas, bem como pela comprovação das precariedades dos trabalhos em que isto não se evidencia.

Nesse sentido, Haddad e Di Pierro (1999) lembram que a educação de adultos sempre compreendeu um conjunto diversificado de processos e práticas formais e informais relacionadas com a aquisição ou a ampliação de conhecimentos básicos, competências técnicas e profissionais ou de habilidades socioculturais.

A partir da Lei de Diretrizes e Bases da Educação Nacional, $n^{\circ}$ 9.394/96 (LDBEN) a EJA passou a ser definida como modalidade de Educação Básica nas etapas de ensino fundamental e médio, com 
especificidade própria, devendo receber tratamento adequado para atender aos educandos jovens e adultos, capacitando-os para as exigências do mudo do trabalho. Neste sentido, novos caminhos teóricos e novas metodologias, com capacidade de construir a qualidade do ensino na EJA, se faziam necessários para formar o professorado.

Visando minimizar as dificuldades e atender às novas demandas da formação de professores para atuarem na EJA foi que durante o período de 1998 a 2003, a partir da iniciativa de um grupo de professores do Departamento de Educação do Campus I, ofertou-se um curso de especialização em educação básica de jovens e adultos para qualificar, preferencialmente, professores da rede pública que atuassem na modalidade da educação básica. Posteriormente, houve uma extensão deste curso, sendo oferecida uma turma no Departamento de Filosofia e Ciências Humanas de Juazeiro, sem convênio formal, mas com base em um acordo entre os professores do Departamento e a coordenação do curso. A proposta de especialização foi implantada na UNEB mediante convênio com a CADCT, com recursos da Capes no bojo do Projeto Nordeste.

Esse curso propunha, dentre outros objetivos, "analisar criticamente as tendências atuais e as inovações pedagógicas na área de educação básica de jovens e adultos, possibilitando aos alunos uma ampla compreensão acerca dos problemas, limitações e dificuldades existentes no campo desta modalidade educativa" (DANTAS, 1998).

Essa proposta, na área da educação de jovens e adultos, oportunizava aos cursistas espaços para o enriquecimento cultural, científico, histórico, ampliação de conhecimentos e troca de saberes, indo ao encontro de aspirações profissionais deste coletivo formado por professores e gestores que já atuavam na modalidade de ensino da EJA.

O curso conseguiu colocar no mercado de trabalho 429 profissionais especializados no campo da EJA com potencial para atuar na gestão, na docência, na pesquisa e na extensão. Obteve-se, com este curso, um grande impacto na educação pública, relatado pelos ex-cursistas, haja vista a repercussão e o sucesso obtidos no decorrer desta experiência, tanto em Salvador (com dez turmas) como em Juazeiro (com uma turma), com uma carga horária de 510 horas de trabalho presencial, face à sua proposta curricular desafiadora e à dinâmica empregada (mediante módulos) no desenvolvimento do curso.

Essa experiência vem servindo para nortear outras propostas educativas na área de EJA em nível do departamento, corrigindo equívocos, revendo posições, somando os êxitos e ampliando conhecimentos em busca de uma educação com melhor qualidade.

A partir dessa referência e do impacto já produzido em todo o estado da Bahia, com 429 concluintes inseridos no mercado de trabalho, bem como por todo o conhecimento gerado sobre a temática através de grupos de pesquisa, trabalhos defendidos na graduação e pós-graduação - muitos destes resultando em reconhecidas publicações nacionais e internacionais - é que se propôs a criação do Mestrado Profissional em EJA, no Departamento de Educação - Campus I, considerando o compromisso dessa universidade com a Educação e, nela, com a formação profissional e a produção científica para além do cenário regional, consolidando-se enquanto instância de excelência acadêmica e de difusão do conhecimento.

Dessa forma, a Universidade do Estado da Bahia vem atendendo a essa demanda com ampla experiência nessa modalidade de ensino, desde suas intervenções nas disciplinas de Estágio Supervisionado, quando a realidade da Educação de Jovens e Adultos é trazida para a sala de aula para articular teoria e prática, avaliando as condições, eficácia e implicações, passando pelas diversas pesquisas de Monografias de Conclusão de Curso, pesquisas institucionais de seus pesquisadores, $\mathrm{o}$ Curso de Pós-graduação em Educação de Jovens e Adultos, em nível de Especialização, que durante quase uma década foi responsável pela formação de diversos profissionais que realizaram várias pesquisas sobre as realidades que vivenciavam nas escolas públicas nesta modalidade de ensino. Nesse cenário, destaca-se o papel da Educação de Jovens e Adultos não só através do curso de especialização como também mediante as ações do Núcleo de Educação de Jovens e Adultos da UNEB, interferindo e implementando, paulatinamente, uma mudança da realidade do analfabetismo na Bahia com vistas à inserção do indivíduo na sociedade no que se refere à sua participação nas diversas instâncias sociais. 
Tendo em vista as pesquisas sobre o ensino-aprendizagem na EJA e a necessidade de uma formação continuada e específica dos professores que atuam na modalidade da EJA, considerando as demandas sociais do país e, principalmente, do Nordeste, foi que o DEDC I da UNEB logrou ter sido recomendada pela Capes uma proposta de criação de um Mestrado Profissional em Educação de Jovens e Adultos, avançando na direção do preenchimento de uma lacuna social que há muito tempo foi constatada, que vem sendo debatida no contexto acadêmico e nos fóruns de EJA, mas ainda não apresentava um retorno satisfatório com ações afirmativas para reverter a situação.

O Programa de Pós-Graduação stricto sensu aparece com a intencionalidade de ampliar e diversificar a oferta de curso no campo da EJA, intentando superar a situação crítica em que se encontrava a formação de professores frente à existência de uma oferta dispersa para uma demanda desatendida como já denunciava Flecha (1990).

O Mestrado Profissional em Educação de Jovens e Adultos do DEDC I, consoante com as suas áreas de concentração, vem centrando as suas atividades no desenvolvimento do(a) profissional, do(a) educador(a) de EJA, desenvolvendo formação continuada, articulando as suas atividades nas seguintes linhas de atuação: formação de professores e pesquisadores de EJA; realização de pesquisas empíricas e projetos de intervenção que contribuam para transformação efetiva dos espaços de EJA no Estado da Bahia; realização de cursos de formação continuada em EJA; formação de profissionais do Estado e dos municípios baianos envolvidos na gestão da EJA; desenvolvimento de pesquisas que explicitem as causas dos problemas da EJA em nosso estado; desenvolvimento de pesquisas sobre os impactos da EJA na vida dos formados; desenvolvimento de projetos pedagógicos de intervenção na EJA; realização de Parcerias universidade-escola; universidade/secretaria de educação.

O Mestrado em EJA focado em três grandes áreas de concentração, quais sejam, educação, meio ambiente e trabalho, formação de professores e políticas públicas, gestão educacional e tecnologias da informação e da comunicação vem gerando grupos de pesquisa no departamento, fomentando trabalhos de extensão, incentivando a realização de seminários e encontros anuais e aumentando a produção de pesquisa sobre a temática da educação de jovens e adultos.

Vale ressaltar que predomina no curso uma forte implicação com as ideias freireanas que perpassam nas disciplinas trabalhadas, notadamente na Disciplina Fundamentos Teóricos das Concepções Freireanas, na qual se discute boa parte da obra deste grande educador, organizada em dois períodos, antes e depois do exílio de Freire, em uma relação dialógica com os alunos. Os pesquisadores do Instituto Paulo Freire fazem inserção no curso participando de Seminários Temáticos, de Conferências e Palestras em eventos, em Aulas Inaugurais, como parte da programação inerente ao Mestrado.

A criação de um Mestrado Profissional em EJA na Bahia contempla uma demanda importante da educação brasileira, ou seja, a educação de jovens e adultos, até então muito discutida e analisada, mas que ainda apresentava poucas ações relativas a uma formação adequada do(a) profissional que atua(rá) nesse segmento.

As principais contribuições deste Mestrado podem ser visualizadas mediante os temas e objetos que permeiam os projetos de pesquisa dos alunos, colocados em prática com a orientação dos docentes do curso, em diferentes comunidades interioranas onde os alunos vivem e trabalham, que resultarão, certamente, em forte inserção social nos municípios baianos.

\section{Temas dos Trabalhos de Conclusão de Curso}

Dentre os principais temas apresentados pelos discentes em formato dissertação, se destaca a temática formação de professores como a mais recorrente, com estudos dirimidos à formação continuada, formação profissional, percurso formativo e formação nas licenciaturas; o currículo também desponta como uma das preocupações dos alunos, o que nos reporta ao alerta de Ventura (2012, p. 76) ao dizer que "as licenciaturas consideram a formação de professores uma atividade de menor importância e que poucos cursos propõem disciplinas específicas sobre EJA nos currículos das licenciaturas". Daí a relevância do estudo destas 
temáticas mostrando a situação crítica em que se encontra a formação de professores, sobretudo no que concerne à educação de jovens e adultos, desprestigiada nas licenciaturas, mas também nos cursos de Pedagogia, onde aparece apenas como componente EJA.

\section{Objetos de estudo do MPEJA}

Em relação aos objetos de estudo de alunos e professores, reiteramos a formação como mais recorrente, com pesquisas nas variantes: formação continuada, formação profissional, formação do professor, percurso de formação, propostas pedagógicas e programas formativos; o currículo também desponta como centro dos estudos, ao lado da gestão das políticas públicas. As pesquisas, via de regra, são realizadas em escolas de educação básica, com professores, gestores e alunos que são os protagonistas da EJA.

Machado (2009, p. 5), em pesquisa acerca do estado da arte entre 1986 e 1998, sobre a prática e a formação de professores, ressalta que

[...] as pesquisas que tratam mais especificamente das práticas dos professores que atuam em EJA, assim como aquelas que trataram da formação de professores, apontam, em sua maioria, como um dos suportes utilizados para seu referencial teórico um resgate do histórico da Educação Popular e da Educação de Jovens e Adultos no Brasil.

Essa orientação é confirmada nos trabalhos de pesquisa dos alunos do MPEJA, quando muitos exploram em seus estudos a contextualização da EJA no âmbito da educação popular.

Os trabalhos de conclusão de curso vêm reforçando a inserção deste Mestrado na educação básica, denotando a preocupação com os principais problemas e demandas dos alunos, nos seus municípios de origem, que vai além do espaço da sala de aula, perpassam os aspectos estritamente pedagógicos como fatores socioambientais, questões relacionadas com o trabalho, direitos humanos, dentre outras.

Vêm também preencher uma lacuna já denunciada por Dantas (2009) sobre a escassez de pesquisas no campo da EJA, sobretudo acerca da formação e da prática dos professores, o que denota a necessidade de um incremento das investigações nesta área. $\mathrm{O}$ estudo sobre o estado da arte das pesquisas em EJA na Bahia nos últimos 10 anos, realizado por Laffin e Dantas (2015), denuncia também as poucas produções existentes sobre este campo de pesquisa e de prática pedagógica em nosso estado.

Entre os principais desafios que se colocam para o Mestrado Profissional em EJA, em consonância com o coletivo dos MPE, podemos destacar em âmbito geral: a) pautar discussões sobre temas de interesse dos MPE no FORPRED, na ANPED e na Capes; b) captar recursos junto aos órgãos de fomento, uma vez que os MPE não têm direito aos recursos destinados pela Capes aos programas de pós-graduação; c) contribuir para o fortalecimento dos MPE em educação; d) articular ensino, pesquisa e extensão no âmbito das atividades desenvolvidas nos programas; e) colaborar para instituir redes de pesquisa no âmbito dos Mestrados Profissionais em Educação; f) articular ações em conjunto com os Mestrados Profissionais e os Programas Acadêmicos na definição e instituição de uma política pública de formação e de pós-graduação em uma nova configuração, pautada pelos interesses e demandas dos professores e que venha a ser assumida pelos órgãos competentes.

Dentre os desafios de âmbito específico podemos salientar: colaborar para implantar uma política pública de estado para a EJA; garantir a infraestrutura básica (espaço físico, recursos humanos, equipamentos, materiais permanentes e de consumo) para o pleno funcionamento do Programa; desenvolver pesquisas no Programa que tenham aplicabilidade e impacto nas comunidades envolvidas nos projetos e propostas dos estudantes; captar recursos para garantir as ações e atividades planejadas para o biênio 2016-2017; concretizar os convênios que estão em processo de negociação (Instituto Federal Baiano (IFBAIANO), Instituto Federal da Bahia (IFBA), Secretaria de Educação do Estado e Secretaria Municipal de Lauro de Freitas); fortalecer os convênios internacionais com a Universidade do Minho e de Coimbra; publicar quatro livros com temáticas versando sobre EJA neste biênio; credenciar novos professores para ministrar as disciplinas do Programa nas áreas que necessitam de docentes; promover o III Encontro 
Internacional de Educação e Educação de Jovens e Adultos (ALFAEEJA), em parceria com a Universidade Federal de Santa Catarina, Universidade de Coimbra e Universidade do Minho; trabalhar na direção de aumentar a nota do Programa na primeira avaliação quadrienal feita pela Capes; deslanchar o projeto de pesquisa com a Rede Internacional de Pesquisa em Educação para o Trabalho (RIET) da Argentina; realizar o II Seminário Internacional sobre Direitos Humanos na UNEB, em articulação com várias instituições promotoras.

Nessa direção, o MPEJA pretende ser um espaço de qualificação e um lugar de formação continuada do(a) profissional da EJA, em que a relação teoria-prática terá um espaço de reflexão-ação sobre esta modalidade de ensino. É importante salientar também a proposta de aproximação da universidade com as redes públicas de ensino por meio da contribuição para a formação dos(as) seus(suas) professores(as) e da troca de experiências advindas das reflexões e pesquisas desenvolvidas no mestrado, assim como de parcerias a serem instituídas entre a UNEB e as redes públicas para o desenvolvimento de novas práticas pedagógicas na EJA.

\section{Considerações Finais}

Os MPE têm desempenhado funções relevantes em nível regional e nacional no que se refere à formação de profissionais da educação e se consolida como espaço formador, sem a pretensão de sobrepor ou diferenciar-se dos mestrados acadêmicos, pois nasceram em razão das demandas sociais e formativas em todo o território brasileiro, e através dos coordenadores, professores e alunos conquistaram espaços na ANPED e no FORPRED (nacional e regional), bem como conceberam e legitimaram, nacionalmente, o Fórum Nacional dos Mestrados Profissionais (FOMPE), na sua terceira versão (Salvador, Juiz de Fora e São Paulo) e instigaram mudanças nos critérios da Ficha de Avaliação e no texto do Documento de área, concernentes ao APCN dos MPE.

Alinhado às problemáticas que demandam superações, os MPE se tornam realidade no cenário brasileiro e demonstram preocupação nos seguintes aspectos:

a) Correlação das pesquisas e projetos com o enfrentamento dos problemas da educação básica nas Redes Públicas;

b) Preocupação no desenvolvimento teórico-metodológico do campo científico, relacionado às áreas de concentração e às linhas de pesquisa;

c) Perspectiva no desenvolvimento de projetos de intervenção para superação dos desafios da oferta, gestão e qualidade dos sistemas públicos de educação;

d) Metodologia aplicada no desenvolvimento de estudos e projetos de pesquisa que resultem em intervenções no âmbito político, organizacional e cultural, para o enfrentamento dos desafios da área de educação;

e) Esforço no entendimento e na composição dos formatos de Trabalhos de Conclusão de Curso e dos produtos gerados pelos mesmos, com potencial inovador aos processos educacionais;

f) Conscientização da importância da produção técnica para o quadro docente e para a formação dos discentes;

g) Esforço para o cumprimento de prazos nas qualificações e defesas;

h) Parcerias com Secretarias de Educação, Institutos Federais, ONGs e outros espaços formais e não formais;

i) Formação contínua do quadro docente sobre legislação e avaliação dos MPE, no âmbito do CNE e da Capes;

j) Parcerias inter e intrainstitucionais no Brasil e com universidades da América e da Europa;

k) Relação com alunos e professores da graduação, pós-graduação e comunidade externa, entre outros aspectos importantes à consolidação dos MPE.

O cenário atual dos MPE mostra sua itinerância de superações e conquistas, uma vez que as propostas, nesta modalidade, não param de crescer a cada ano na área de Educação da Capes, mesmo considerando a falta de incentivo financeiro; as limitações de muitos pesquisadores à avaliação destes mestrados no âmbito da Capes; a dificuldade de entendimento de alguns professores, destes cursos, acerca da Pesquisa Aplicada; o desconhecimento da comunidade acadêmica sobre outros formatos 
de TCC, mencionados no art. $7^{\circ}$ da Portaria $n^{\circ}$ 17/2009 da Capes; a formação do quadro docente ainda concentrada em programas acadêmicos, o que reflete na composição de novos MPE.

Corroboramos com Menandro (2010, p. 371) ao encerrar seus comentários sobre esta modalidade stricto sensu, em seu artigo Mestrado Profissional: você sabe com quem está falando?, no qual propõe que as universidades possam viver a experiência e as dificuldades de implantar um tipo de Mestrado com

[...] características que não o tornam imediatamente reconhecível, sem práticas de comparações hierarquizantes e impróprias entre as diferentes modalidades, nem deve levar ao perigoso raciocínio, segundo o qual, todas as áreas devem ter Mestrados Profissionais.

\section{REFERÊNCIAS}

ANDRÉ, Marli. Pesquisa em Educação: buscando rigor e qualidade. Cadernos de Pesquisa, n. 113, p. 51-64, jul. 2001.

ARAÚJO, Kátia Soane Santos. A rádio da escola na escola da rádio: uma proposta de educação científica desenvolvida com alunos da escola municipal Roberto Santos/SSA-Ba. 2015. $134 \mathrm{f}$. Trabalho de Conclusão de Curso (Mestrado em Gestão e Tecnologias Aplicadas à Educação) - Mestrado Profissional Gestão e Tecnologias Aplicadas à Educação (GESTEC), Universidade do Estado da Bahia (UNEB), Salvador, 2015.

BOUFLEUER, José Pedro. O mestrado profissionalizante em educação: a retomada do debate. Rio de Janeiro: ANPEd, 2003.

BRASIL. Ministério da Educação. Conselho Nacional de Educação. Conselho de Educação Superior (CESu). Parecer CNE/CESu no 977, de 03 de dezembro de 1965. Disponível em: <https://www.capes.gov.br/images/stories/ download/legislacao/Parecer_CESU_977_1965.pdf>. Disponível em: 12 jul. 2016.

Ministério da Educação. Coordenação de Aperfeiçoamento de Pessoal de Nível Superior (Capes). Plano Nacional de Pós-Graduação - PNPG 2011-2020. Brasília, DF: Capes, 2010.

CEVALLOS, Ivete; PASSOS, Laurizete Ferragut. O mestrado profissional e a pesquisa do professor. Revista Diálogo Educação, Curitiba, v. 12, n. 37, p. 803-822, set./dez. 2012.

CORREIA, Sílvia Letícia Costa Pereira. Entre ruas e ladeiras, Engomadeira sou eu! Representações socioespaciais de professores sobre o bairro. 2015. 138 f. Trabalho de Conclusão de Curso (Mestrado em Gestão e Tecnologias Aplicadas à Educação) - Mestrado Profissional Gestão e Tecnologias Aplicadas à Educação (GESTEC), Universidade do Estado da Bahia (UNEB), Salvador, 2015

DANTAS, Tânia. Projeto do Curso de Especialização em Educação Básica de Jovens e Adultos. Salvador: UNEB/FAEEBA, 1998.

Professores de adultos: formação, narrativa autobiográfica e identidade profissional. 2009. 525f. Tese (Doutorado em Educação) - Universidade Autônoma de Barcelona, Barcelona, 2009.

Formação de professores em EJA: uma experiência pioneira na Bahia. Revista da FAEEBA, Salvador, v.21, n. 37, jan./jun. 2012, p.147-162.

FERNANDES, Agnes. Mestrado Profissional: algumas reflexões. Revista Oculum Ensaios, Campinas, SP, v. 12, n. 2, p. 107-109, 2015.

FLECHA, R. Educación de personas adultas: propuesta para los años noventa. Madrid: Roure Editorial, 1990.

Compartindo palavras: el aprendizaje de las personas adultas através del diálogo. Barcelona: Ediciones Paidós Ibérica, 1999.

FLECHA, Ramón; MELLO, Roseli. A formação de educadoras e educadores para um modelo social de educação de pessoas jovens e adultas: perspectiva dialógica. Revista da FAEEBA, Salvador, v. 21, n. 37, p. 39-52, jan./jun. 2012.

FÓRUM NACIONAL DE COORDENADORES DOS PROGRAMAS DE PÓS-GRADUAÇÃO EM EDUCAÇÃO DA ANPEd (FORPRED). Relatório das Condições e Perspectivas dos Mestrados Profissionais em Educação. Goiânia: ANPED/FORPRED, 2013. 


\section{Documento da Comissão do FORPRED para subsidiar a discussão sobre Mestrado Profissional para} a Área de Educação da Capes. Natal: FORPRED, 2011.

FREITAS, Danton de Oliveira. Ensino de geometria e tecnologia: potenciais do audiovisual na formação de professores das séries iniciais do ensino fundamental. 2015. 104 f. Trabalho de Conclusão de Curso (Mestrado em Gestão e Tecnologias Aplicadas à Educação) - Programa de Pós-Graduação Stricto Sensu em Gestão e Tecnologias Aplicadas à Educação (GESTEC), Universidade do Estado da Bahia (UNEB), Salvador, 2015.

GOMES, Kellen Lima. Gestão integrada da informação nos Programas de Pós-Graduação stricto sensu da UNEB: modelagem e operacionalização da plataforma Pandora. 2016. 129 f. Trabalho de Conclusão de Curso (Mestrado em Gestão e Tecnologias Aplicadas à Educação) - Programa de Pós-Graduação Stricto Sensu em Gestão e Tecnologias Aplicadas à Educação (GESTEC), Universidade do Estado da Bahia (UNEB), Salvador, 2016.

HADDAD, S.; DI PIERRO, M. Satisfação das necessidades básicas de aprendizagem de jovens e adultos no Brasil: contribuições para uma avaliação da década da Educação para todos. Brasília, DF: MEC, 1999.

LAFFIN, M. H.; DANTAS, T. A pesquisa sobre a EJA na e da Bahia: aproximações e demandas teórico-metodológicas. Revista Brasileira de Educação de Jovens e Adultos, Salvador, v. 3, n. 6, p.147-173, 2015.

MACHADO, M. M. A prática e a formação de professores na EJA: uma análise de dissertações e teses produzidas no período de 1986 a 1998. 2009. Disponível em:

$<$ http://23reuniao.anped.org.br/textos/1822t.PDF>. Acesso em: 12 jul. 2016.

MARQUES, Waldirene Magna Guimarães Pimentel. Educação profissional: análise da gestão técnico-pedagógica no Centro Territorial de Educação Profissional da Sertão Produtivo - CETEP - Caetité/Bahia. 2015. 115f. Trabalho de Conclusão de Curso (Mestrado em Gestão e Tecnologias Aplicadas à Educação) - Programa de Pós-Graduação Stricto Sensu em Gestão e Tecnologias Aplicadas à Educação (GESTEC), Universidade do Estado da Bahia (UNEB), Salvador, 2015.

MENANDRO, Paulo Rogério Meira. Mestrado Profissional: você sabe com quem está falando? Revista de Administração Contemporânea - RAC, Curitiba, v. 14, n. 2, p. 367-371, mar./abr. 2010. Disponível em: <http://www. anpad.org.br/rac $>$. Acesso em: 21 de junho de 2016.

MENDES, Jordan Santos. CASULO: uma experiência vídeo documentada com alunos da Rede Pública de ensino do Estado da Bahia. 2015. 94f. Trabalho de Conclusão de Curso (Mestrado em Gestão e Tecnologias Aplicadas à Educação) - Programa de Pós-Graduação Stricto Sensu em Gestão e Tecnologias Aplicadas à Educação (GESTEC), Universidade do Estado da Bahia (UNEB), Salvador, 2015.

MENEZES, Cátia Nery. Leitura e escrita: propositiva de intervenção através de dispositivos móveis aos alunos do $3^{\circ}$ e $4^{\circ}$ ano do ensino fundamental I. 2015. 101f. Trabalho de Conclusão de Curso (Mestrado em Gestão e Tecnologias Aplicadas à Educação) - Programa de Pós-Graduação Stricto Sensu em Gestão e Tecnologias Aplicadas à Educação (GESTEC), Universidade do Estado da Bahia (UNEB), Salvador, 2015.

MIRANDA, Marta Rosa Farias de Almeida. Investimentos públicos diretos em educação superior da Bahia: um estudo de caso sobre o sistema estadual de educação superior da Bahia. 2013. 229f. Trabalho de Conclusão de Curso (Mestrado em Gestão e Tecnologias Aplicadas à Educação) - Programa de Pós-Graduação Stricto Sensu em Gestão e Tecnologias Aplicadas à Educação (GESTEC), Universidade do Estado da Bahia (UNEB), Salvador, 2013.

MONTEIRO, Acácia Angélica. O musical Kimera - cidades imaginárias, construído como potencializador do processo de educação musical na escola. 2015. 239f. Trabalho de Conclusão de Curso (Mestrado em Gestão e Tecnologias Aplicadas à Educação) - Programa de Pós-Graduação Stricto Sensu em Gestão e Tecnologias Aplicadas à Educação (GESTEC), Universidade do Estado da Bahia (UNEB), Salvador, 2015.

MOREIRA, Rosângela Patrícia de Sousa. O lugar da pesquisa na educação geográfica: relatos de experiências dos alunos do ensino médio - IFBA/Campus Valença. 2015. 110f. Trabalho de Conclusão de Curso (Mestrado em Gestão e Tecnologias Aplicadas à Educação) - Programa de Pós-Graduação Stricto Sensu em Gestão e Tecnologias Aplicadas à Educação (GESTEC), Universidade do Estado da Bahia (UNEB), Salvador, 2015.

NÓVOA, A. Professores: imagem de um futuro presente. Lisboa: Educa, 2009.

OLIVEIRA, Grimaldo Lopes de. GESMOODLE - Ferramenta de mediação tecnológica e acompanhamento do processo de aprendizagem dos alunos em cursos de graduação a distância da Universidade do Estado da Bahia (UNEB). 2013. 117 f. Trabalho de Conclusão de Curso (Mestrado em Gestão e Tecnologias Aplicadas à Educação) 
- Programa de Pós-Graduação Stricto Sensu em Gestão e Tecnologias Aplicadas à Educação (GESTEC), Universidade do Estado da Bahia (UNEB), Salvador, 2013.

PEREIRA, M. L. de C. A construção do letramento na educação de jovens e adultos. 2. ed. Belo Horizonte: Autêntica/FHC-FUMEC, 2007.

SILVA. Euzebio Raimundo da. A avaliação institucional da UNEB e suas implicações na política de pessoal e no reconhecimento e valorização dos servidores técnicos administrativos no período de 2006 a 2013. 2015. 372 f. Trabalho de Conclusão de Curso (Mestrado em Gestão e Tecnologias Aplicadas à Educação) - Programa de Pós-Graduação Stricto Sensu em Gestão e Tecnologias Aplicadas à Educação (GESTEC), Universidade do Estado da Bahia (UNEB), Salvador, 2015.

SOARES, L. Educação de jovens e adultos: diretrizes curriculares nacionais. Rio de Janeiro: DP\&A, 2002.

RAMIREZ, Pedro Alejandro Herrera. Plataforma Pandora: desenvolvimento do sistema integrado de gestão da informação da pós-graduação stricto sensu/UNEB. 2016. 67f. Trabalho de Conclusão de Curso (Mestrado em Gestão e Tecnologias Aplicadas à Educação) - Programa de Pós-Graduação Stricto Sensu em Gestão e Tecnologias Aplicadas à Educação (GESTEC), Universidade do Estado da Bahia (UNEB), Salvador, 2016.

RIBEIRO, Renato Janine. Ainda sobre o Mestrado Profissional. Revista Portuguesa e Brasileira de Gestão RPBG, v. 5, n. 3, p. 313-315, dez. 2006.

ROMÃO, José Eustáquio; MAFRA, Jason Ferreira. Mestrado Profissional: crônica de uma morte anunciada... Revista Plurais, v. 1, n. 2, p. 10-23, abr./ago. 2016.

VENTURA, J. A EJA e os desafios da formação docente nas licenciaturas. Revista da FAEEBA - Educação e Contemporaneidade, Salvador, v. 21, n. 37, p. 71-82, jan./jun. 2012.

VIANA, Gilvânia Clemente. Re(composição) documental para o projeto do software educacional jogo-simulador Kimera: cidades imaginárias. 2016. 143 f. Trabalho de Conclusão de Curso (Mestrado em Gestão e Tecnologias Aplicadas à Educação) - Programa de Pós-Graduação Stricto Sensu em Gestão e Tecnologias Aplicadas à Educação (GESTEC), Universidade do Estado da Bahia (UNEB), Salvador, 2016.

VIRMOND, Marcos. Mestrado Profissional: uma síntese. Salusvita, Bauru, SP, v. 21, n. 2, p. 117-130, 2002.

Recebido em: 18/07/2016

Aprovado em: 01/10/2016 